\section{Edycaçäa Tat}

ARTIGO

\section{Editor}

Maria Inês Côrte Vitoria PUCRS, RS, Brasil

\section{Equipe Editorial}

Pricila Kohls dos Santos PUCRS, RS, Brasil

Marcelo Oliveira da Silva PUCRS, RS, Brasil

Carla Spagnolo PUCRS, RS, Brasil Rosa Maria Rigo PUCRS, RS, Brasil

\title{
PUCRS e Newcastle University: uma experiência de internacionalização a partir da construção de uma exposição conjunta entre o Museu de Ciências e Tecnologia e o Great North Museum: Hancock
}

\author{
PUCRS and Newcastle University: an internationalization experience \\ from the construction of a joint exhibition between the \\ Science and Technology Museum and the Great North Museum: Hancock
}

José Luís Schifino Ferraroa, Melissa Guerra Simões Pires ${ }^{b}$, Rosemary Sadami Arai Shinkaic

RESUMO: O presente artigo tem como objetivo apresentar a parceria estabelecida entre a Pontifícia Universidade Católica do Rio Grande do Sul (PUCRS) e a Newcastle University (NU) para a elaboração conjunta de uma exposição sobre Evolução. Essa aproximação entre o Museu de Ciências e Tecnologia da PUCRS (MCT-PUCRS) e o Great North Museum: Hancok (GNM) possibilitou uma abertura para que ambas universidades estreitassem suas relações e para a elaboração de estratégias e ações para internacionalização. Ao propor um trabalho conjunto - concepção, planejamento e troca de expertises - sobre o tema, optou-se pela utilização das coleções científicas de ambos museus para o ensino da evolução no sentido de promover uma melhor compreensão das modificações climáticas sob uma perspectiva ecomuseológica.

Palavras-chave: internacionalização; Museu de Ciências e Tecnologia da PUCRS; Great North Museum; Newcastle; ecomuseologia.

ABSTRACT: The present article has the aim to present the partnership between the Pontifical Catholic University from Rio Grande do Sul (PUCRS) and Newcastle University (NU) for the elaboration of a joint exhibition on Evolution. This approach between the Science and Technology Museum from PUCRS (MCT-PUCRS) and the

a Doutor em Educação. Professor da Faculdade de Biociências e do Programa de Pós-graduação em Educação em Ciências e Matemática da Pontifícia Universidade Católica do Rio Grande do Sul (PUCRS).

b Doutora em Medicina. Professora da Faculdade de Biociências e Diretora do Museu de Ciências e Tecnologia da PUCRS.

c Doutora em Clínica Odontológica. Professora da Faculdade de Odontologia e Assessora-chefe para Assuntos Internacionais e Interinstitucionais da PUCRS. 
Great North Museum: Hancock (GNM) allowed the two universities to get closer and elaborate strategies and actions for internationalization. By proposing a joint work - conception, planning and expertise exchange about the theme, the option was to use the scientific collections from both museums to understand the climate changes under an ecomuseologic perspective.

Keywords: internationalization; Science and Technology Museum from PUCRS; Great North Museum; Newcastle; ecomuseology.

\section{Introdução}

$\mathrm{D}$ esde sua origem o processo de internacionalização tem sido pensado pelas universidades como ponto chave para sua expansão em termos de coprodução em pesquisa. Segundo Morosini (2006), foi a partir do processo de globalização - principalmente na década de 1990 - que a internacionalização da educação superior vem ganhando cada vez mais força. Porém, com a categorização da educação como serviço, tem-se verificado um deslocamento a partir de sua regulamentação como tal pela Organização Mundial do Comércio (OMC) (DIAS SOBRINHO, 2005). Desde então, a importância de pensa-la, também, voltada às questões relacionadas ao ensino passou a ser pauta nas universidades.

Muitas políticas de internacionalização direcionadas à educação foram colocadas em prática a partir do momento em que houve uma crescente valorização do conhecimento pelo Estado, o que exigiu uma adequação das universidades e centros universitários que - ao fomentá-la - passaram, inevitável e positivamente, a formar profissionais cosmopolitas (IANNI, 2005). A partir disso, inúmeros acordos, convênios e outros tipos de parcerias foram estabelecidos entre as instituições de ensino - principalmente a partir da orientação de documentos da Organização para Cooperação e Desenvolvimento Econômico (OCDE) e da Organização das Nações Unidas para a Educação, a Ciência e a Cultura (UNESCO) que pautam os rumos da educação superior -, além da necessidade e demandas inerentes à própria contemporaneidade no que tange a organização e a elaboração de estratégias para a formação desses estudantes (GOERGEN, 2010).

\section{Discussão: 0 relato da parceria}

Nesse contexto de internacionalização - cujo foco é também o ensino -, a Pontifícia Universidade Católica do Rio Grande do Sul (PUCRS) e a Newcastle University (NU) inovam ao colocarem no epicentro de sua parceria 
seus museus, a saber, respectivamente, Museu de Ciências e Tecnologia da PUCRS (MCT-PUCRS) e Great North Museum: Hancock (GNM). Os museus universitários convertem-se como estratégicos, pois além de atuarem no âmbito da pesquisa e do próprio ensino - focos para a internacionalização - também atendem as demandas das atividades extensionistas das universidades. Em assim sendo, a realidade museal acaba por contemplar todas as dimensões da triangulação ensino-pesquisa-extensão, tendo uma atuação não apenas junto à comunidade acadêmica, mas também junto ao público externo.

PUCRS e NU estabeleceram uma parceria por meio do edital Institutional Skills 2015-2016, promovido pelo British Council do Brasil com financiamento do Newton Fund, um dos mais importantes fundos de financiamento e fomento de pesquisa e inovação do Reino Unido. Consiste em "uma iniciativa do governo britânico que visa promover o desenvolvimento social e econômico dos países parceiros, por meio de pesquisa, ciência e da tecnologia" (BRITISH COUNCIL, 2016a). O edital Institutional Skills tem como objetivo apoiar projetos relacionados ao treinamento, capacitação e/ou engajamento comunitário de funcionários e/ou colaboradores de instituições brasileiras" em diversas áreas (BRITISH COUNCIL, 2016b), tais como: agricultura; ciências sociais; clima e meio ambiente; doenças infecciosas negligenciadas; economia inclusiva, ensino de disciplinas relacionadas às Ciências e Matemática na Educação Básica (STEM - Science, Technology, Engineering, and Mathematics); e transformações urbanas (BRITISH COUNCIL, 2016b). A proposta foi elaborada no eixo temático do ensino de disciplinas relacionadas às Ciências e Matemática na Educação Básica que incluía a popularização da ciência e o ensino fora da escola, mote adequado para a inserção dos museus no projeto.

A partir dessa dimensão do ensino "fora da escola" é que a possibilidade de uso dos museus passou a ser considerada na elaboração do projeto a ser proposto. Os museus são espaços não formais de educação, e, portanto, podem contribuir para o aprendizado de estudantes ao possibilitá-los observar e/ou interagir com materiais que complementem sua aprendizagem formal. Esse movimento permite que os próprios alunos sejam de certa forma empoderados, pois se tornam sujeitos protagonistas de sua aprendizagem. Ao referirem-se, especificamente, aos museus de Ciências Cazelli et al. (1999, p.8) enfatizam a contribuição dos museus nesse sentido ao ressaltaram "o papel da ação do sujeito da aprendizagem" no âmbito museal.

O projeto intitulado "The use of museums scientific collections for teaching evolution and understanding of environmental changes from the ecomuseologic perspective" começou a se tornar realidade a partir do momento em que houve conhecimento sobre edital Institutional Skills. A equipe da Coordenadoria Educacional da MCT-PUCRS foi contatada pela assessora-chefe da Assessoria para Assuntos Internacionais e Interinstitucionais da PUCRS (AAIIPUCRS) que apresentou o edital como possibilidade para financiamento para algum projeto que pudesse envolver o MCT-PUCRS. Após a leitura e o estudo sobre o edital, foram estabelecidos os primeiros contatos entre PUCRS e NU. 
A aproximação entre o MCT-PUCRS e GNM deu-se pelo fato de que ambos possuem coleções biológicas. Como uma das premissas para a execução do projeto seria o uso das coleções científicas - apresentando-as e aproximando-as dos visitantes -, optou-se pela elaboração e construção não apenas de uma exposição científica, mas duas (simultaneamente em Porto Alegre e Newcastle) onde em cada uma delas, os respectivos museus trabalhariam conceitos em evolução a partir dos materiais que cada um deles que dispõe em suas coleções.

A ideia de utilizar uma perspectiva ecomuseológica partiu de parte da equipe de trabalho e está relacionada às pesquisas desenvolvidas na School of Arts and Cultures da NU na área de museologia. Hugues de Varine-Bohan foi o criador do termo "ecomuseu", ainda nos anos 1970, quando então Diretor do Conselho Internacional de Museus (ICOM). Tal conceito encontra-se impregnado pela ideia de um "museu integral", conectado e integrado com a comunidade (DUARTE, 2014) o que vai ao encontro da realidade do MCT-PUCRS e do GNM, pois ambos já possuem uma inserção local muito forte e muito positiva que pode ser verificada pelo número de escolas e visitantes que recebem durante o ano.

No caso em específico do MCT-PUCRS Ferraro e Giglio (2014) ressaltam que o mesmo tem a divulgação científica e a popularização da ciência como objetivos no âmbito do ensino, da pesquisa e da extensão (FERRARO; GIGLIO, 2014). Ainda, pelo fato de ser um museu interativo, "aproxima o público [...] de experimentos construídos para facilitar a compreensão de princípios e leis científicas a partir da interação" (FERRARO; GIGLIO, 2014, p. 334). Muito da inserção do MCT-PUCRS na comunidade deve-se ao tipo de ações educativas que o mesmo organiza atendendo escolas, professores e estudantes tanto da rede pública, quanto da rede privada de ensino.

\section{Resultados preliminares e perspectivas para o projeto}

A primeira fase do projeto foi constituída de duas missões de trabalho, onde profissionais da PUCRS e da NU puderam trocar experiências. A equipe do MCT-PUCRS que esteve presente em Newcastle teve uma agenda dividida em duas partes: concomitantemente a uma pauta universitária - para conhecimento da estrutura da NU - houve outra museológica, a partir das visitas aos museus e centros de ciências geridos pela Tyne \& Wear Archives \& Museums (TWAM) parceira da NU. Durante a missão realizada em Newcastle foram organizadas inúmeras reuniões de trabalho onde foi apresentada a proposta do projeto com algumas concepções iniciais da equipe da PUCRS para que o trabalho em conjunto pudesse começar a ser planejado e organizado.

Ainda em Newcastle foi discutida a concepção da exposição conjunta em termos conceituais, avaliando a proposta do projeto e levando em consideração as demandas dos dois museus (ambos com desafios muito similares). Ainda, avaliaram-se os espaços de ambos, os materiais das coleções que poderiam ser usados no sentido de cumprimento 
da temática proposta e a maneira como estes seriam apresentados ao público no sentido de que os mesmos pudessem observar a partir do estudo da evolução, do entendimento sobre o fenômeno evolutivo, uma possibilidade para compreensão dos efeitos das mudanças ambientais e seus efeitos sobre a vida na Terra.

Na segunda missão de trabalho, representantes da NU e da TWAM estiveram em Porto Alegre para conhecer a estrutura da PUCRS e do MCT-PUCRS. Da mesma forma, como na primeira missão de trabalho, houve inúmeras reuniões para o planejamento do trabalho em conjunto. Foi decidido que a montagem da exposição seria baseada no conceito da irradiação adaptativa com a ideia de que se pudesse compreender o contexto do aparecimento dos grandes grupos de animais - e suas relações filogenéticas - a partir da comparação de sua estrutura óssea em face às modificações ambientais. As equipes educacionais e curadores de ambos museus trabalharam em conjunto. Aprovou-se o projeto museográfico para a exposição de Porto Alegre e, a partir dela, passará a ser inspirada a concepção e organização (tanto em termos técnicos quanto museográficos) da exposição de Newcastle.

Estão previstas mais duas missões para o acompanhamento conjunto da construção das exposições, o que demanda, principalmente um trabalho da curadoria de linguagem. Ainda, após inauguradas, serão avaliadas as possibilidades de realização de práticas educativas que envolverão alunos de graduação e pós-graduação na preparação de oficinas para estudantes do ensino fundamental e médio. Professores da rede pública e privada também serão beneficiados com formações para a utilização da exposição em suas aulas no museu.

Como fruto da parceria entre PUCRS e NU, no primeiro semestre de 2016, já foram organizadas na PUCRS duas palestras internacionais cujas temáticas referiam-se aos ecomuseus e às práticas educativas em ciências que ocorrem no GNM. Ambas foram abertas à comunidade acadêmica e ao público externo em parceria com o Sistema Estadual de Museus do estado do Rio Grande do Sul (SEM). Com a proximidade entre PUCRS e NU, muitas outras conexões envolvendo as universidades puderam ser mapeadas e a possibilidade de estreitamento de laços entre ambas em termos de intercâmbio de alunos (graduação, mestrado e doutorado sanduíches) e professores (pós-doutorado) torna-se cada vez mais frequente. Ainda, há a possibilidade do estabelecimento de cursos de extensão à distância de curta duração envolvendo professores da PUCRS e NU.

Cabe ainda lembrar que tal aproximação acaba, também, por fomentar uma disseminação cultural entre Brasil e Inglaterra. Referências às cidades de Porto Alegre e Newcastle serão consideradas para que uma parte da cultura brasileira seja disseminada em Newcastle, bem como parte da cultura britânica seja de igual maneira também disseminada em Porto Alegre.

A parceria institucional entre a PUCRS e a Newcastle University é um exemplo de colaboração equitativa e estratégica para ambas as universidades. As relações individuais de colaboração bilateral entre pesquisadores 
evoluíram para conexões de longa duração, mobilidade de alunos e desenvolvimento de projetos de pesquisa conjuntos em diversas áreas das Ciências, Engenharias, Tecnologias, Humanidades, Ciências Sociais, Saúde, Economia e, agora, com o MCT-PUCRS. Não há no mundo outra instituição parceira com a qual a PUCRS tenha colaboração tão ampla e diversificada institucionalmente, com tantos pesquisadores e docentes diferentes envolvidos. Ao longo dos últimos cinco anos, houve conexão entre mais de cinquenta docentes, pesquisadores e técnicos administrativos da PUCRS e da Newcastle University.

Com a visita da Cônsul Geral Adjunta e Diretora de Comércio e Investimento do Reino Unido no Brasil, este e outros projetos adquirem um status estratégico. Expandir as relações entre Brasil e Reino Unido em termos de coprodução e coautoria científica, assim como para a elaboração de práticas educativas, converte-se em um interessante indicador para o desenvolvimento conjunto de ambas nações. A partir de parcerias como essa, a PUCRS reafirma sua vontade de expandir sua marca e suas relações com outras instituições internacionais de educação superior mantendo-se como referência em educação e pesquisa no Brasil e no mundo.

\section{Referências}

BRITISH COUNCIL. Disponível em: <https://www.britishcouncil.org.br/atividades/educacao/newton-fund>. Acesso em: 27 de junho de 2016.

BRITISH COUNCIL. Disponível em: <https://www.britishcouncil.org.br/newton-fund/chamadas/institutional-skills-2015-2016>. Acesso em: 27 de junho de 2016.

CAZELlI, Sibele; QUEIROZ, Glória; ALVES, Fátima; FALCÃO, Douglas; VALENTE, Maria Esther; GOUVÊA, Guaracira; COLINVAUX, Dominique. Tendências pedagógicas das exposições de um museu de ciência. In: Encontro Nacional de Pesquisa em Educação em Ciências, 2., 1999, Valinhos-SP. Atas... São Paulo: Associação Brasileira de Pesquisa em Educação em Ciências, 1999. p. 1-14.

DIAS SOBRINHO, José. Educação Superior, globalização e democratização. Revista Brasileira de Educação. Rio de Janeiro: ANPED, v. 28, p. 164-173, 2005.

DUARTE, Alice. Nova museologia: os pontapés de saída de uma abordagem ainda inovadora. Revista Museologia e Patrimônio, v. 6, n. 2, p. 99-117, 2014.

FERRARO, José Luís Schifino; GIGLIO, Roberta. O Museu como espaço de transversalidade. Educação Por Escrito, v. 5, n. 2, p. 333-345, 2014.

GOERGEN, Pedro. Educação superior na perspectiva do sistema e do plano nacional de educação. Educação e Sociedade, v. 31 , n. 112 , p. $895-917,2010$. 
IANNI, Octavio. A sociedade global. 12. ed. Rio de Janeiro: Civilização Brasileira, 2005.

MOROSINI, Marília Costa. Estado do conhecimento sobre internacionalização da educação superior - conceitos e práticas. Educar, Curitiba, n. 28, p. 107-124, 2006.

Recebido em: julho/2016

Aceito em: novembro/2016

Endereço para correspondência:

José Luís Schifino Ferraro

Av. Ipiranga, 6681

90619-900 Porto Alegre, RS, Brasil

$<$ jose.luis@pucrs.br> 